\title{
Differences in Cardiovascular and Hypothalamic-Pituitary-Adrenal Axis Functions between High-Altitude Visitors and Natives during a Trek on the Annapurna Circuit
}

\author{
Jai Y. Park ${ }^{a}$ Tae K. Hwang ${ }^{\text {b Hyun K. Park }}{ }^{c}$ Ryun S. Ahn ${ }^{\text {d }}$ \\ Departments of a Anesthesiology and Pain Medicine, and ${ }^{b}$ Orthopedics, The Armed Forces \\ Capital Hospital, 'Department of Adapted Physical Education, Korea National Sport University, and \\ ${ }^{\mathrm{d}}$ Graduate School of Integrative Medicine, CAH Medical University, Seoul, Republic of Korea
}

\section{Key Words}

Cortisol awakening response $\cdot$ Hypobaric hypoxemia .

Cardiovascular responses $\cdot$ Sherpas $\cdot$ Sea-level natives

\begin{abstract}
Objective: Differences in the cardiovascular and hypothalamic-pituitary-adrenal (HPA) axis functions at high altitudes (HAs) between visitors to and natives of HA were examined. Methods: The cardiovascular functions and peripheral oxygen saturation $\left(\mathrm{SPO}_{2}\right)$ were monitored, and the cortisol awakening response (CAR) and nighttime cortisol concentration (NCC), as indices of the HPA axis function, were determined in 25 trekkers and 21 Sherpas during an Annapurna circuit trek. Results: $\mathrm{SPO}_{2}$ decreased less in the Sherpas than in the trekkers at $\mathrm{HAs}(3,540,3,800$, and $4,800 \mathrm{~m})$. Blood pressure and heart rate in the Sherpas changed concurrently during the trek; however, a tachycardic response occurred without changes in blood pressure in the trekkers at HAs. The CAR and NCC at HAs in the trekkers differed from those observed at $1,100 \mathrm{~m}$ and those observed at HAs in the Sherpas. The trekkers exhibited an elevated morning cortisol level at 3,540 and 3,800 $\mathrm{m}$, a heightened CAR at 4,800 m, and an elevated NCC at $3,800 \mathrm{~m}$. Alteration of the CAR resulted in an
\end{abstract}

increase in the integrated volume of cortisol released within the first hour after awakening (CARauc) in the trekkers. The changes in $\mathrm{SPO}_{2}$ occurred concurrently with the changes in the CARauc and the heart rate in the trekkers. Conclusions: The alterations of CAR occurred at HAs where blood pressure levels reached a peak plateau, which is associated with an increase in heart rate at HAs in the trekkers. The CAR was unaltered in the Sherpas during the trek.

(C) 2014 S. Karger AG, Basel

\section{Introduction}

High altitude (HA) locations, such as the Andes and the Himalayas, are attractive destinations for adventurous trekkers and mountaineers. However, these individuals will inevitably face HA-induced, life-threatening 'real' stress if they wish to ascend to altitudes $>3,000 \mathrm{~m}$. This stress is referred to as hypobaric hypoxemia. Because the partial pressure of inspired oxygen $\left(\mathrm{PiO}_{2}\right)$ decreases as the altitude increases, the availability of oxygen is reduced at HAs. When the $\mathrm{PiO}_{2}$ is reduced to $13.3 \mathrm{kPa}$ (at $3,000 \mathrm{~m}$ ), the majority of HA visitors who normally reside near sea level experience acute mountain sickness (AMS) and hy-

\begin{tabular}{ll}
\hline KARGER & $\begin{array}{l}\text { ○ 2014 S. Karger AG, Basel } \\
0028-3835 / 14 / 0992-0130 \$ 39.50 / 0 \quad \text { Karger }\end{array}$ \\
E-Mail karger@karger.com & $\begin{array}{l}\text { This is an Open Access article licensed under the terms of the } \\
\text { Creative Commons Attribution-NonCommercial 3.0 Un- } \\
\text { ported license (CC BY-NC) (www.karger.com/OA-license), } \\
\text { applicable to the online version of the article only. Distribu- } \\
\text { tion permitted for non-commercial purposes only. }\end{array}$
\end{tabular}

Ryun S. Ahn

Graduate School of Integrative Medicine

CAH Medical University

Seoul 135-907 (Republic of Korea)

E-Mail ryunsup@gmail.com 
poxic cardiorespiratory responses, such as an increased respiratory rate, heart rate (HR), blood pressure (BP), and cardiac output [1].

Physiological responses to hypobaric hypoxemia are initiated by $\mathrm{O}_{2}$-sensitive chemoreceptors in the carotid bodies [2]. A decreased $\mathrm{O}_{2}$ concentration in the blood activates carotid bodies to a degree that corresponds with the severity of the decrease in $\mathrm{O}_{2}$ [3]. The signal from these receptors travels via the carotid sinus nerves to the nucleus of the solitary tract [4], and the hypothalamic paraventricular nucleus (PVN) integrates the chemosensory afferent signals [5]. Because the hypothalamic PVN is an important integrative center containing neurons that regulate autonomic and neuroendocrine function [6], it is reasonable to suppose that the hypothalamic-pituitary-adrenal (HPA) axis, the sympathetic nervous system, and cardiovascular function can be synchronously activated under hypobaric hypoxemic conditions.

Substantial field research has studied sympathetic activity and HPA axis activity at HAs. However, urinary and circulating levels of norepinephrine and epinephrine have differed between studies [7,8]. Resting plasma ACTH and cortisol levels have also varied between studies and have variously been reported to be increased [911], unchanged [12], or decreased [13]. Considerable variations in duration of stay and altitude among these studies may explain these differing results.

Pruessner et al. [14] observed a sharp increase in cortisol levels within the first hour after waking in normal subjects. This phenomenon, known as the cortisol awakening response (CAR), is a reliable marker of the function of the HPA axis in human beings [15]. Based on studies of the communication of circadian signals between the hypothalamic suprachiasmatic nucleus (SCN) and the PVN [16], the CAR is considered to be a part of the circadian cortisol rhythm. It is also a representation of the SCN-mediated activation of HPA axis function, possibly via the neuroendocrine neurons of the PVN, which stimulate ACTH secretion in the anterior pituitary, and the sympathetic splanchnic nerves innervating the adrenal glands, which increase the adrenal sensitivity to ACTH $[15,17]$. Meanwhile, the altered (i.e. blunted or heightened) CAR in subjects reporting perceived stress, work overload, or anticipation of upcoming demands [17] indicates that ongoing and upcoming stresses can affect the CAR.

Although it is generally recognized that hypobaric hypoxemia increases sympathetic activity and cardiovascular function [7], previous field studies did not address how the HPA axis and cardiovascular system respond to different altitudes during a trek to HAs in visitors to and natives of HA regions. Given the role of the hypothalamic PVN in shaping integrated hypobaric hypoxemic stress responses and generating neural and humoral circadian signals $[5,6,16]$, we hypothesized that adrenocortical cortisol secretion would be affected by hypobaric hypoxemia and that endogenous rhythm-mediated cortisol secretion would change while ascending to altitude in visitors to HA regions. To test the hypothesis, we joined a trekking group as a team physician. During the ascending $(1,100,3,540$, and $4,800 \mathrm{~m})$ and descending $(3,800 \mathrm{~m})$ sections of a trek on the Annapurna circuit, CAR and nighttime cortisol concentration (NCC) levels were measured in trekkers who normally reside at sea level and in HA natives (Sherpas). Cardiovascular function parameters, including systolic BP (SBP) and diastolic BP (DBP), HR, and peripheral oxygen saturation levels $\left(\mathrm{SPO}_{2}\right)$ were also monitored.

\section{Subjects and Methods}

\section{Subjects}

The Korean Alpine Federation (KAF) recruited applicants for the Annapurna circuit trek. Following a face-to-face interview (by J.Y.P.), applicants who previously or currently had systemic disorders, such as hypertension, diabetes, anemia, or abnormal body mass index (BMI $\leq 18$ or $\geq 28$ ) were excluded from the trekking group. The trekking group was composed of 26 males and $11 \mathrm{fe}$ males who had no previous HA trek experience or had not performed a HA trek in the past year. The KAF asked a Nepalese travel agent to recruit guides, porters and cooks or cooking assistants for the trekking group. 32 Sherpas and 39 native Nepalese assistants joined and supported the trekkers from January 11, 2011 to January 24, 2011.

Among the trekkers, all of the females were initially excluded from the present study because BP and HRs are influenced by the menstrual phase in hypobaric hypoxic conditions [18]. To make the groups ethnically homogenous, 39 native Nepalese assistants were excluded from the present study. We therefore initially included 26 male trekkers and 32 Sherpas for the present study. The included Sherpas informed us that they were born and raised in Namche Bazaar, Lukla, or Khumbu and had been working as trekking guides, porters, or cooks for 2-19 years in the Nepalese Himalayas. All of the male trekkers and Sherpas were given instructions regarding the procedures for the present study and informed of their right to freely withdraw from the study at any time. Among the initially included Sherpas, 6 refused to participate in the study, and 3 dropped out of the study.

Acetazolamide, acetaminophen, or phosphodiesterase type 5 (PDE5) inhibitors were administered to certain trekkers who suffered from HA-induced symptoms. Because of the stimulatory effect of PDE5 inhibitors on cortisol secretion [19], 1 trekker who was administered a PDE5 inhibitor was excluded from the present study. In total, 25 male trekkers, aged $14-59$ years (mean 38.4 ) and 21 Sherpas, aged $16-39$ years (mean 27.2 ) participated in the pres- 
ent study. None of the participant trekkers or Sherpas had ever taken hormone replacement therapy; moreover, none had taken oral glucocorticoids within 3 months prior to the initiation of the study. Two authors of this study joined the trekking group as the team physician (J.Y.P.) and his assistant (H.K.P.). No participants dropped out during the Annapurna circuit trek.

This study was conducted in accordance with the Declaration of Helsinki and complies with the ethical standards relating to human research in the Republic of Korea (ROC); the protocol was approved by the IRB of the Korea Armed Forces Capital Hospital and all participants gave their informed consent.

\section{$\mathrm{SPO}_{2}$ and Cardiovascular Function Monitoring and Saliva \\ Sample Collection}

$\mathrm{SPO}_{2}, \mathrm{SBP}, \mathrm{DBP}$, and HR were monitored within the first hour after awakening from nocturnal sleep. These were obtained from both the trekkers and Sherpas inside the lodges, which were located on the ascending route at Syanje $(1,100 \mathrm{~m})$, Manang $(3,540 \mathrm{~m})$, and the Throng Pedi high camp $(4,800 \mathrm{~m})$, and on the descending route at the Muktinath lodge $(3,800 \mathrm{~m})$. The trekking group had an allotted time frame of 5 days for the ascent from Syanje to Manang and another 3 days for the ascent from Manang to the Throng Pedi high camp. $\mathrm{SPO}_{2}$ and $\mathrm{HR}$ data were obtained using a finger pulse oximeter (Pulsox-2; Konica Minolta, Osaka, Japan). SBP and DBP were monitored using a wrist check automatic blood pressure monitor (EW278; Matsushita Electric Works, Tokyo, Japan).

Four saliva samples were collected following arrival and prior to leaving the lodges where $\mathrm{SPO}_{2}$ and cardiovascular function were monitored. One saliva sample was collected prior to sleep to determine NCC, and three samples were collected consecutively the following morning to determine the CAR. These three samples were collected immediately upon awakening $(0 \mathrm{~min})$ and at 30 and 60 min after awakening. Therefore, four saliva samples were collected from each subject at each lodge. Each set of four samples is defined as a batch, and four batches were collected from each subject for the present study.

Following dinner, all of the members of the trek were informed about the following day's trek schedule, such as the wake-up and departure times and the estimated time of arrival at the next destination. The participants went to sleep in the lodge (at 19:30 h at the lodge at 4,800 $\mathrm{m}$, and at approximately 20:00-20:30 $\mathrm{h}$ at the other lodges) and used individual sleeping bags. The participants woke up to an alarm clock that had been set for the informed wake-up time (04:30 h at the lodge at $4,800 \mathrm{~m}$, and approximately 05:00-05:30 $\mathrm{h}$ at the other lodges). Three light-emitting diode camping lanterns (battery-operated, $4 \mathrm{~W}, 300 \mathrm{~lm}$ ) were turned on after the alarm clock went off to illuminate the inside of the lodge room. The interior morning temperature of the lodge was $+15^{\circ} \mathrm{C}$ at Syanje, $-3.5^{\circ} \mathrm{C}$ at Manang, $-7.5^{\circ} \mathrm{C}$ at the high camp, and $-3.5^{\circ} \mathrm{C}$ at Muktinath.

None of the trekkers or Sherpas drank alcohol or smoked until the trek was over. During the sample collection period, all of the participants were requested to refrain from eating food, drinking fluids, and brushing their teeth and rinsing their mouths with water prior to each sample collection. Saliva was collected without external stimulation but with muscle movement and expectoration into a collecting tube (Simport, Inc., Beloeil, Qué., Canada). The tubes were kept outside of the lodge after screwing the cap on tightly. The saliva samples were kept in an insulated box with ice packs for transport from Pokhara airport in Nepal to the laboratory in Seoul, ROK.

After the debris was removed from each sample, the saliva samples were stored at $-70^{\circ} \mathrm{C}$. The samples were thawed and centrifuged $\left(10,000 \mathrm{~g}, 15 \mathrm{~min}, 4^{\circ} \mathrm{C}\right)$ to precipitate mucins. The supernatant was collected and stored at $-70^{\circ} \mathrm{C}$ until the assay was performed. All of the saliva samples were analyzed at the Hormone Research Center at the Chonnam National University.

\section{Measurement of Salivary Cortisol}

Salivary cortisol levels were determined using RIA, as has been previously described [20]. Cortisol was exogenously added at 5.0 or $20.0 \mathrm{nmol} / \mathrm{l}$ into different samples of charcoal-stripped saliva, and the concentrations were determined to be $4.8 \pm 0.3 \mathrm{nmol} / \mathrm{l}$ $(\mathrm{n}=20)$ or $22.3 \pm 1.7 \mathrm{nmol} / \mathrm{l}(\mathrm{n}=20)$, respectively. The inter-assay coefficients of variation, as assessed from quality controls with cortisol concentrations of 2.8 and $13.4 \mathrm{nmol} / \mathrm{l}$, were 7.1 and $8.6 \%$, respectively $(n=12)$. The intra-assay coefficients of variations for the same pool were less than $10 \%(\mathrm{n}=15)$. The analytical sensitivity for the cortisol level was $0.3 \mathrm{nmol} / \mathrm{l}$.

\section{Data Analysis}

To further analyze the CAR, the integrated volume of cortisol released over the waking period was calculated for each subject as the area under the cortisol curve with respect to baseline from immediately upon awakening $(0 \mathrm{~min})$ to $60 \mathrm{~min}$ after awakening (CARauc) [21]. This calculation was performed using GraphPad Prism version 5.01 for Windows (GraphPad Software, San Diego, Calif., USA). The net increases in cortisol levels within the first 30 min after awakening (CARi) were also calculated for each subject, as described in a previous study [14]. As in previous studies [22, 23], a normal CAR in the present study was defined as an increase in cortisol levels of at least $2.5 \mathrm{nmol} / \mathrm{l}$ between the period immediately following awakening and $30 \mathrm{~min}$ after awakening (i.e. at least a $2.5 \mathrm{nmol} / 1$ increase in CARi). It is well documented that a typical CAR cannot be observed if the first saliva sample is collected following a delay of more than 10 min after awakening [23]. We observed negative CARi values in every one or two batches of saliva samples from the trekkers and Sherpas. These results were considered to be due to a delay between waking and collection of the first sample [24]. These abnormal data were excluded from all of the further data analyses, and the other data that were collected from the corresponding subject at the same lodge, such as $\mathrm{SPO}_{2}, \mathrm{SBP}$, DBP, and HR, were also excluded. After exclusion procedures, complete data ( $\mathrm{SPO}_{2}, \mathrm{SBP}, \mathrm{DBP}, \mathrm{HR}, \mathrm{CARi}, \mathrm{CARauc}$, and NCC) were obtained from $18,14,16$, and 19 of the 25 trekkers and from $13,11,11$, and 14 of the 21 Sherpas at $1,100,3,540,3,800$, and 4,800 $\mathrm{m}$, respectively.

Parametric or non-parametric statistical tests were used after performing the Shapiro-Wilk W test for normality. The differences between the trekkers and Sherpas with respect to the examined parameters (i.e. $\mathrm{SPO}_{2}, \mathrm{SBP}, \mathrm{DBP}, \mathrm{HR}, \mathrm{CARi}, \mathrm{CARauc}$, and NCC) were analyzed using two-tailed $t$ tests or the Mann-Whitney test. The effect of the altitude on the cortisol profiles was analyzed using a two-way ANOVA. One-way ANOVAs were used to analyze the differences between the cortisol concentrations and the additional parameters that were obtained at the examined altitudes. A post hoc test was performed to determine specific altitude differences. The relationships between $\mathrm{SPO}_{2}$ and cardiac function parameters, between $\mathrm{SPO}_{2}$ and HPA axis function parameters, and between the 
cardiovascular and HPA axis function parameters were analyzed using Pearson's correlation test. The statistical calculations were performed using SAS version 9.1 (SAS Institute, Inc., Cary, N.C., USA), and a $p$ value $<0.05$ was considered significant. All of the results given are means \pm SEM.

\section{Results}

\section{Changes in $\mathrm{SPO}_{2}$ and Cardiovascular Variables in} Trekkers and Sherpas

We monitored $\mathrm{SPO}_{2}, \mathrm{SBP}, \mathrm{DBP}$, and $\mathrm{HR}$ within the first hour after awakening from nocturnal sleep in the lodges, which were located at different altitudes on ascending $(1,100,3,540$, and 4,800 $\mathrm{m})$ and descending $(3,800 \mathrm{~m})$ routes on the Annapurna circuit (fig. 1). A one-way ANOVA revealed an effect of altitude on $\mathrm{SPO}_{2}$ $\left(\mathrm{F}_{3,64}=26.15, \mathrm{p}<0.001\right), \mathrm{SBP}\left(\mathrm{F}_{3,64}=2.97, \mathrm{p}<0.05\right), \mathrm{DBP}$ $\left(\mathrm{F}_{3,64}=3.21, \mathrm{p}<0.05\right)$, and $\operatorname{HR}\left(\mathrm{F}_{3,64}=6.28, \mathrm{p}<0.01\right)$ of the trekkers. On average, there were 9.5 and $25.8 \%$ decreases in $\mathrm{SPO}_{2}$ at 3,540 and 4,800 m, respectively, compared with the values that were observed in the trekkers at $1,100 \mathrm{~m}$ (fig. 1a). Tukey's post hoc test revealed that SBP, DBP, and HR increased significantly in the trekkers after the ascent from 1,100 to $3,540 \mathrm{~m}$ ( $\mathrm{p}<0.05$ for all analyses) (fig. $1 \mathrm{~b}-\mathrm{d}$ ). We observed average increases of 11.7, 11.0, and $13.2 \%$ in SBP, DBP, and HR, respectively, after the ascent from 1,100 to $3,540 \mathrm{~m}$ (fig. $1 \mathrm{~b}-\mathrm{d}$ ). No further increases in SBP or DBP were observed after the ascent from 3,540 to $4,800 \mathrm{~m}$ (fig. $1 \mathrm{~b}, \mathrm{c}$ ); however, HR increased (5.6\%) after the ascent from 3,450 to $4,800 \mathrm{~m}$ (fig. $1 \mathrm{~d}$ ).

In Sherpas, we observed an effect of altitude on $\mathrm{SPO}_{2}$ $\left(\mathrm{F}_{3,46}=56.1, \mathrm{p}<0.001\right), \operatorname{SBP}\left(\mathrm{F}_{3,46}=3.05, \mathrm{p}<0.05\right), \mathrm{DBP}$ $\left(\mathrm{F}_{3,46}=3.21, \mathrm{p}<0.05\right)$, and $\operatorname{HR}\left(\mathrm{F}_{3,46}=6.28, \mathrm{p}<0.01\right)$. Tukey's post hoc test revealed that $\mathrm{SPO}_{2}$ at the examined HAs $(3,540,3,800$, and 4,800 m) was decreased significantly compared with $1,100 \mathrm{~m}$ ( $\mathrm{p}<0.05$ for all analyses; fig. 1a). SBP increased by 4.6 and $6.8 \%$, and DBP increased by 10.5 and $17.0 \%$ after the ascents to 3,540 and $4,800 \mathrm{~m}$, respectively, compared with the values that were observed at 1,100 m (fig. 1b, c). Interestingly, HR changed slightly after the ascent from 1,100 to $3,540 \mathrm{~m}$ (fig. 1d), but HR increased significantly after the ascent from 3,450 to $4,800 \mathrm{~m}$. HR increased by an average of $18.0 \%$ after the ascent from 3,450 to $4,800 \mathrm{~m}$ (fig. 1d).

At HAs $\left(3,540,3,800\right.$ and 4,800 m), $\mathrm{SPO}_{2}$ was significantly lower in the trekkers than the Sherpas ( $p<0.05$ for all analyses, two-tailed t test) (fig. 1a). SBP and DBP values were comparable between the trekkers and Sherpas (fig. 1b, c), but HR was significantly higher in the trekkers than the Sherpas at these HAs $(\mathrm{p}<0.01$ for all analyses,

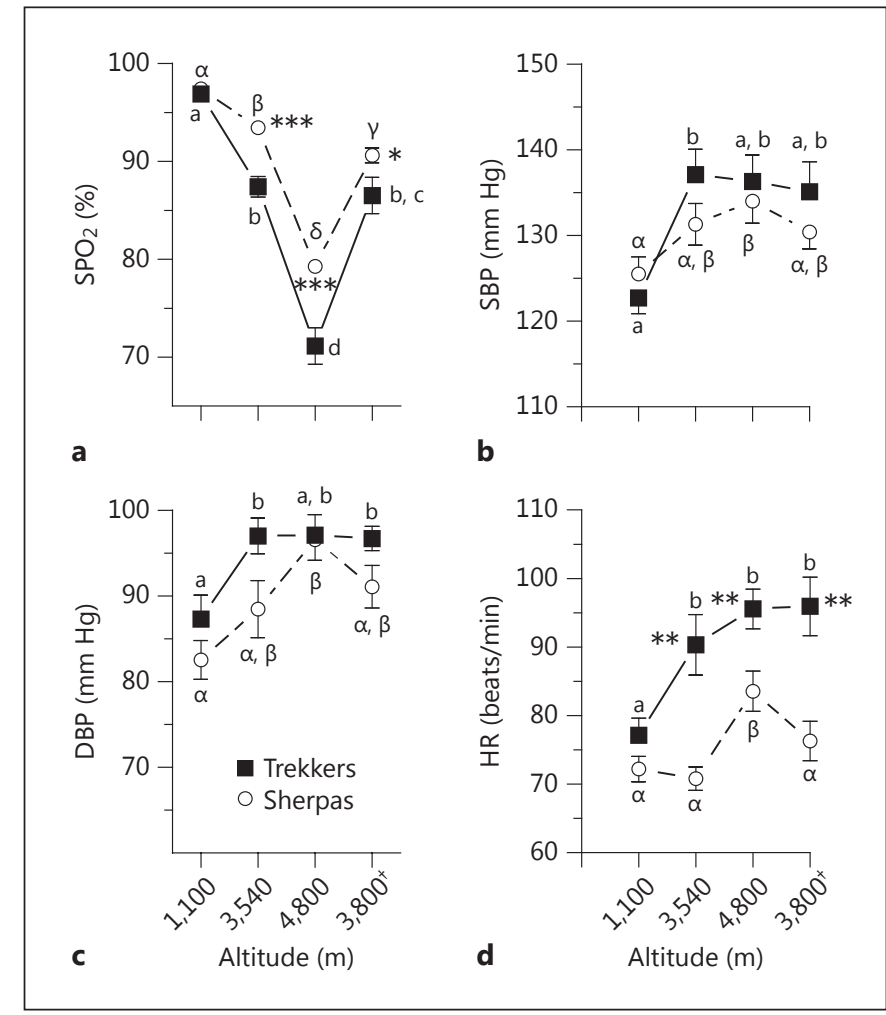

Fig. 1. Alterations in $\mathrm{SPO}_{2}$ (a), $\mathrm{SBP}(\mathbf{b}), \mathrm{DBP}(\mathbf{c})$, and $\mathrm{HR}(\mathbf{d})$ in trekkers and Sherpas. $\mathrm{SPO}_{2}, \mathrm{SBP}, \mathrm{DBP}$, and HR were monitored within the first hour after awakening from nocturnal sleep at the lodges, which were located on the ascending route at Syanje $(1,100 \mathrm{~m}$, trek day 1$)$, Manang $(3,540 \mathrm{~m}$, trek day 5$)$, and the Throng Pedi high camp $(4,800 \mathrm{~m}$, trek day 8$)$, and on the descending route at the Muktinath lodge (3,800 m, trek day 9). Different Latin letters among the trekkers or Greek letters among the Sherpas indicate values that are significantly different from one another $(\mathrm{p}<0.05)$ based on Tukey's post hoc test. Each point represents the mean \pm SEM. The asterisks denote the level of significance; $^{*} \mathrm{p}<0.05$; $^{* *} \mathrm{p}<0.01{ }^{* * *} \mathrm{p}<0.0001$ (based on a two-tailed $\mathrm{t}$ test) when comparing trekkers with Sherpas. ${ }^{\dagger}$ Lodge located on the descending route.

two-tailed t test) (fig. 1d). These results indicated that both the trekkers and Sherpas were faced with hypobaric hypoxemic conditions during their trek on the Annapurna circuit; however, the cardiovascular response to hypobaric hypoxemia differed between the trekkers and Sherpas.

\section{Changes in the Cortisol Secretion in Trekkers and \\ Sherpas during Their Annapurna Circuit Trek}

We determined the cortisol secretion at different altitudes on ascending $(1,100,3,540$ and $4,800 \mathrm{~m})$ and descending $(3,800 \mathrm{~m})$ routes of the Annapurna circuit in trekkers and Sherpas (fig. 2). In the trekkers, a two-way 
Fig. 2. Alterations in cortisol secretion in trekkers (a) and Sherpas (b). Cortisol concentrations were determined in the saliva samples collected from the trekkers and Sherpas inside the lodges, which were located on the ascending route at Syanje (1,100 m, trek day 1$)$, Manang (3,540 m, trek day 5), and the Throng Pedi high camp $(4,800 \mathrm{~m}$, trek day 8$)$ and on the descending route at the Muktinath lodge $(3,800 \mathrm{~m}$, trek day 9). Each point represents the mean \pm SEM.

Fig. 3. Differences in the CARi (a) and CARauc (b) between trekkers and Sherpas. Each bar represents the mean \pm SEM. Bars denoted with different Latin letters among the trekkers or Greek letters among the Sherpas indicate values that are significantly different from one other $(\mathrm{p}<0.05)$. Significant differences $* \mathrm{p}<0.05,{ }^{* *} \mathrm{p}<0.01$ and ${ }^{* * *} \mathrm{p}<0.0001$ between trekkers and Sherpas. ${ }^{\dagger}$ Lodge located on the descending route.
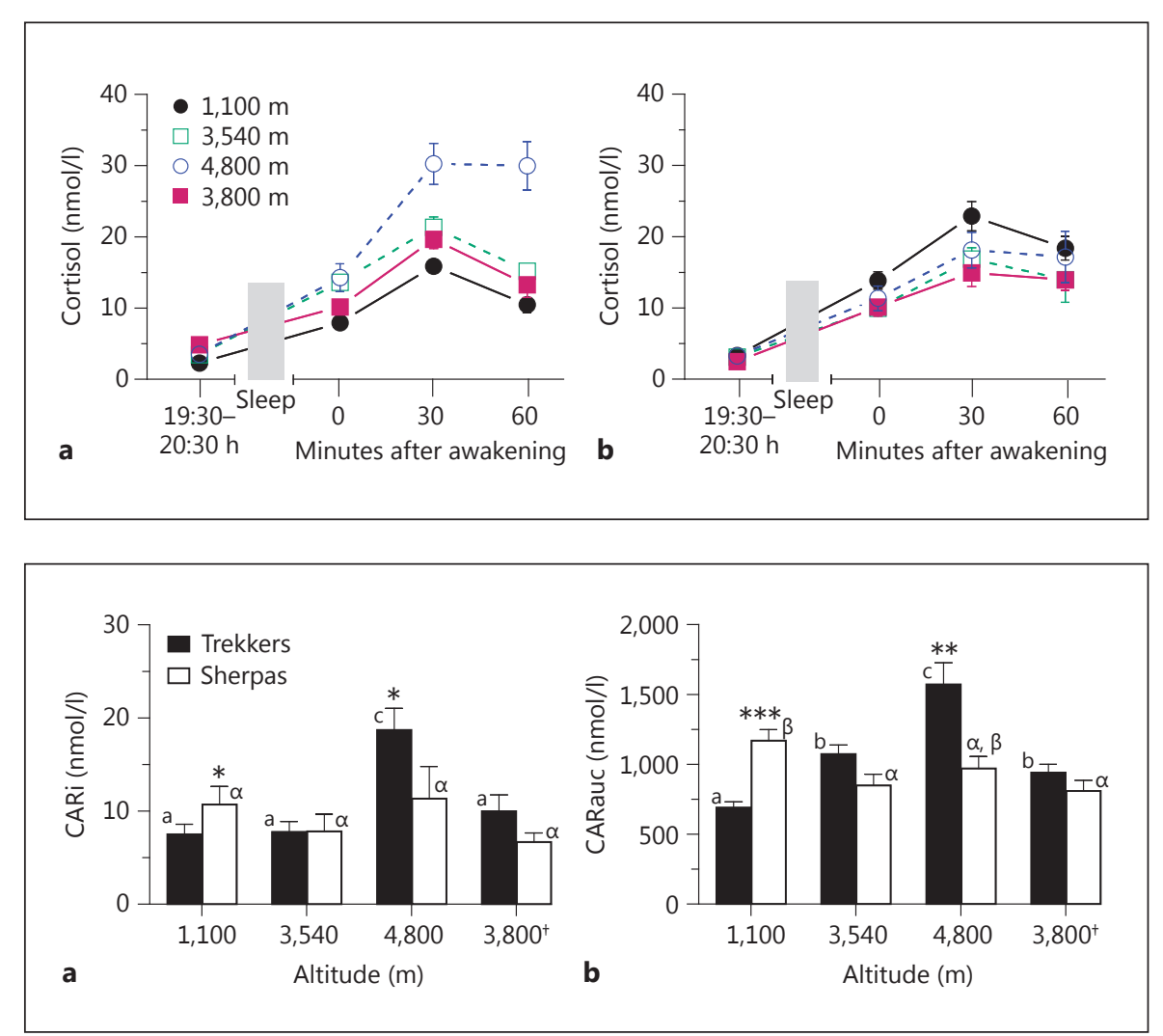

ANOVA revealed the following findings: a significant group effect $\left(\mathrm{F}_{3,252}=28.1, \mathrm{p}<0.0001\right)$, which reflects the influence of altitudes on the levels of cortisol secretion; a significant time effect $\left(\mathrm{F}_{3,252}=90.1, \mathrm{p}<0.0001\right)$, which reflects examined time-related variations of the cortisol levels, and a significant time-by-group interaction effect $\left(\mathrm{F}_{9,252}=5.7, \mathrm{p}<0.0001\right)$, which indicates the influence of altitudes on the patterns of cortisol secretion (fig. 2a). Additional analyses revealed that altitudes of 3,540 and $3,800 \mathrm{~m}$ influenced the levels of cortisol secretion ( $\mathrm{p}<$ 0.05 for all analyses) but not the patterns of cortisol secretion ( $p>0.05$ for all analyses) (fig. 2a). However, an altitude of 4,800 $\mathrm{m}$ influenced both the levels and patterns of cortisol secretion ( $\mathrm{p}<0.001$ for all analyses) (fig. 2a). We observed a significant effect of altitude on the NCC in the trekkers $\left(\mathrm{F}_{3,63}=6.70, \mathrm{p}<0.001\right)$.

In Sherpas, a two-way ANOVA revealed that levels of cortisol secretion were influenced by attitudes (group effect: $F_{3,180}=4.1, p<0.01$ ) and time points (time effect: $\left.\mathrm{F}_{3,180}=50.6, \mathrm{p}<0.0001\right)$, but the patterns of cortisol secretion at the examined altitudes were comparable to one another (time by group interaction effect: $\mathrm{F}_{9,180}=0.5$, $\mathrm{p}=0.84)$ (fig. 2b). Additional analyses demonstrated that the levels of cortisol secretion were similar at HAs $(3,540$, 3,800 and $4,800 \mathrm{~m}$ ) in Sherpas (group effect: $F_{2,132}=1.1$, $\mathrm{p}=0.31$ ) (fig. 2b). These results indicated that HPA axis activity during the trek on the Annapurna circuit was different between the trekkers and Sherpas, and endogenous rhythm-mediated cortisol levels and patterns were influenced by altitudes in the trekkers.

\section{Differences in the CAR between Trekkers and Sherpas}

Altitude effects on the CAR in the trekkers and Sherpas were analyzed using auxiliary indices for the CAR (i.e. CARi and CARauc) (fig. 3). In the trekkers there was a significant effect of altitude on the CARi (Kruskal-Wallis test, $\mathrm{H}=10.49, \mathrm{p}<0.0001$ ), and Dunn's post hoc test revealed that the CARi was significantly higher at $4,800 \mathrm{~m}$ than at other examined altitudes ( $\mathrm{p}<0.05$ for all analyses) (fig. 3a). In Sherpas, however, there was no effect of altitude on the CARi (Kruskal-Wallis test, $\mathrm{H}=3.53$, $\mathrm{p}=0.32$ ) (fig. 3a). We also observed that the CARi was different between the trekkers and Sherpas at 1,100 and 4,800 m. The CARi was higher in the Sherpas at 1,100 m but was higher in the trekkers at 4,800 m (fig. 3a). No differences in the CARi were observed between the trekkers and 
Table 1. Relationship between $\mathrm{SPO}_{2}$, cardiovascular variables, and auxiliary parameters for cortisol secretion in trekkers and sherpas during their trek on the Annapurna circuit

\begin{tabular}{clcll}
\hline & $\mathrm{SPO}_{2}$ & CARauc & CARi & NCC \\
\hline Trekkers & & & & \\
$\mathrm{SPO}_{2}$ & & $-0.56^{* *}$ & $-0.36^{* *}$ & -0.30 \\
$\mathrm{SBP}$ & $-0.31^{\dagger, *}$ & $0.33^{*}$ & 0.02 & 0.19 \\
$\mathrm{DBP}$ & -0.13 & $0.43^{* *}$ & 0.20 & $0.49^{* *}$ \\
$\mathrm{HR}$ & $-0.49^{* *}$ & $0.48^{* *}$ & $0.48^{* *}$ & $0.37^{* *}$ \\
Sherpas & & & & \\
SPO & & 0.25 & -0.6 & 0.17 \\
SBP & -0.24 & -0.15 & -0.02 & -0.26 \\
DBP & $-0.35^{*}$ & -0.2 & 0.19 & 0.04 \\
HR & $-0.52^{*}$ & -0.06 & 0.03 & 0.06 \\
\hline
\end{tabular}

${ }^{\dagger}$ Pearson's correlation coefficient $(\rho) ;{ }^{*} \mathrm{p}<0.05 ;{ }^{* *} \mathrm{p}<0.001$.

Sherpas at 3,540 and 3,800 m (fig. 3a). These results indicated that altitudes of $4,800 \mathrm{~m}$ influenced the pattern of CAR in the trekkers but not in the Sherpas.

There was a significant effect of altitude on the CARauc in both the trekkers (Kruskal-Wallis test, $\mathrm{H}=31.19$, $\mathrm{p}<0.001$ ) and Sherpas (Kruskal-Wallis test, $\mathrm{H}=14.92$, $\mathrm{p}<0.01$ ) (fig. 3b). Dunn's post hoc test demonstrated that the CARauc at HAs was significantly higher than that at $1,100 \mathrm{~m}$ in the trekkers ( $\mathrm{p}<0.05$ for all analyses) (fig. 3b), and the CARauc at $1,100 \mathrm{~m}$ was significantly higher than that at HAs in Sherpas ( $p<0.05$ for all analyses) (fig. 3b). The CARauc was different between the trekkers and Sherpas. The CARauc was higher in Sherpas at $1,100 \mathrm{~m}$ but was higher in the trekkers at 4,800 m (fig. 3a). No differences in the CARauc were observed between the trekkers and Sherpas at 3,540 and 3,800 m (fig. 3b). These results indicate that HAs influenced the CARauc in the trekkers but not in the Sherpas.

\section{Relationship between $\mathrm{SPO}_{2}$, Cortisol Secretions,} and Cardiovascular Function during the Ascending Section of the Annapurna Circuit Trek in Trekkers and Sherpas

The relationships between $\mathrm{SPO}_{2}$, auxiliary indices for cortisol secretion (CARauc, CARi, and NCC), and parameters of cardiovascular function (SBP, DBP, and HR) were determined in the trekkers and Sherpas during the ascending section of the trek on the Annapurna circuit (table 1). In the trekkers, $\mathrm{SPO}_{2}$ was correlated with SBP and HR and with the CARauc and CARi. We also observed that the CARauc was correlated with SBP, DBP, and HR and the CARi and NCC was correlated with HR (table 1).

In Sherpas, $\mathrm{SPO}_{2}$ was correlated with $\mathrm{DBP}$ and $\mathrm{HR}$, but not with any auxiliary indices of cortisol secretion. No correlations were observed between auxiliary indices of cortisol secretion (CARauc, CARi, and NCC) and parameters of cardiovascular function (SBP, DBP, and HR) (table 1). These results indicated that the HPA axis and cardiovascular responses to hypobaric hypoxemia in trekkers were different from those in the Sherpas and that the HPA axis and cardiovascular functions concurrently changed in response to hypobaric hypoxemia in the trekkers during their trek on the Annapurna circuit.

\section{Discussion}

In the present field study, we first determined changes in endogenous rhythm-mediated cortisol secretion (i.e. CAR and NCC) and cardiovascular function in visitors to and natives of HA regions during a trek on the Annapurna circuit. Previous field studies observed that exposure to altitudes $(>2,000 \mathrm{~m})$ causes an increase in the levels of circulating cortisol in sea-level resident subjects $[9,11]$. We observed changes in the CAR in the trekkers at HAs $(3,540,3,800$ and $4,800 \mathrm{~m})$ compared with $1,100 \mathrm{~m}$. Although the CAR in the trekkers can be confounded by trekking-associated variables, for example, prior-day emotional stress [25] and upcoming workloads [26], a significant correlation between the CARauc and $\mathrm{SPO}_{2}$ indicated that hypobaric hypoxemia plays a causative role in the alterations of CAR among the trekkers.

In addition to ACTH-induced stimulation of cortisol secretion, non-ACTH factors, such as neuropeptides and catecholamines, modulate the adrenal sensitivity to ACTH, which induces the dissociation between ACTH and cortisol levels and facilitates glucocorticoid release from adrenal glands under stressful conditions [27]. Previous animal studies demonstrated that carotid sinus nerve dissection delays the rise in plasma cortisol in response to acute hypoxemia without affecting the ACTH levels [28]. Additionally, elevated cortisol concentrations are independent from ACTH but are dependent on splanchnic innervation of the adrenal glands in prolonged hypoxemia in the fetal sheep [29]. In human beings, field studies have reported that norepinephrine excretion increases progressively during the first few days at an altitude of 4,300 m; circulating epinephrine levels increase within a few hours after arrival at an altitude of $4,300 \mathrm{~m}$ and then decrease slightly [30-32]. Therefore, it is possible 
that an increase in non-ACTH factors released from the sympathoneural and sympathoadrenomedullary systems are associated with alterations of the CAR in the trekkers; an increase in the cortisol level at 3,540 and 3,800 $\mathrm{m}$ and a heightened pattern of cortisol secretion at $4,800 \mathrm{~m}$.

The CARi at 4,800 $\mathrm{m}$ was larger than that at 3,540 and $3,800 \mathrm{~m}$, which was the cause of the heightened pattern of CAR and the increase in the CARauc in the trekkers. Because CARi indicates the rate of cortisol secretion within the first $30 \mathrm{~min}$ after awakening, an increase in the adrenocortical steroidogenesis and an augmented release of cortisol from the adrenal glands are required to produce the larger CARi. The mRNA and protein levels of adrenocortical steroidogenic enzymes are increased in the presence of ACTH [33] or non-ACTH factors such as norepinephrine and epinephrine [34]. Furthermore, it has been demonstrated that adrenal medullary and cortical blood flow increases under hypobaric hypoxemic conditions [35]. An increase in the blood flow of adrenal medullary and cortex in the presence of the $\alpha_{2}$-adrenergic receptor agonist, phenylephrine [36], and under hypoxic conditions was observed in dogs pretreated with dexamethasone to prevent ACTH and corticosteroid changes [37], indicating that an increase in adrenal cortical blood flow is closely associated with sympathetic splanchnic nerve activity in hypobaric hypoxemic conditions. However, another animal study observed that intense hypoxia is required for a significant increase in adrenal blood flow [38]. Therefore, it is hypothesized that the larger CARi at $4,800 \mathrm{~m}$ is a representation of differential HPA axis response to severe hypobaric hypoxemic conditions. The sympathoneural system may support adrenocortical function through an increase in the level of adrenocortical steroidogenic enzymes and adrenocortical blood flow at $4,800 \mathrm{~m}$ in the trekkers.

A previous field study has observed that plasma cortisol concentrations are not further increased after arrival at 5,040 $\mathrm{m}$ following a 4-week stay at 3,500 $\mathrm{m}$ in sea-level residents, suggesting that once acclimatization is achieved at a lower altitudes, increased secretion of cortisol may not be necessary for acclimatization to the subsequent altitudes [11]. The trekkers and Sherpas in the present study had 3 acclimatization days in Manang (3,540 m). We observed that cortisol levels after awakening were elevated and the pattern of cortisol secretion was heightened after an ascent to higher altitude $(4,800 \mathrm{~m})$ in the trekkers. Therefore, it is possible that alterations in the CAR at $4,800 \mathrm{~m}$ in the trekkers could be considered as a representation of the HPA axis response to HA in unacclimatized subjects.
An increase in HR at HA is related to increased sympathetic activity and concurrently decreased parasympathetic activity [39]. Previous field studies have reported an increase in BP and decrease in the R-R interval after an acute exposure (1 day) to an altitude of 4,970 $\mathrm{m}$ [40]. Additionally, increases in BP, HR, and vascular resistance were correlated with an increase in norepinephrine excretion during the first 8 days of altitude exposure $(4,300 \mathrm{~m})$ [31]. Meanwhile, Stalder et al. [41] observed that morning awakening is associated with a marked increase in cortisol secretion (i.e. CAR) and with an increase in HR; however, they did not observe a relationship between the CAR and HR and the severity of perceived emotional stress in healthy students. We observed that $\mathrm{HR}$ was $90.3 \pm 4.4 \mathrm{bpm}$ at $3,540 \mathrm{~m}$ and that $\mathrm{HR}$ further increased at 4,800 $\mathrm{m}(95.5 \pm 2.9 \mathrm{bpm})$ in the trekkers. There were significant alterations in the CAR at these altitudes, specifically increased CARauc at $3,540 \mathrm{~m}$ and heightened CARi at 4,800 $\mathrm{m}$ in the trekkers. We observed that the changes in these auxiliary indices of the CAR were correlated with the concurrent changes in the cardiovascular functional parameters and $\mathrm{SPO}_{2}$ in the trekkers during the ascent to $4,800 \mathrm{~m}$. The results of previous studies and this study suggest that the HPA axis and cardiovascular functions are relatively independent under normal daily stress conditions; however, they operate in synchrony under hypobaric hypoxemic conditions.

It is generally believed that, among humans, Sherpas are the most elaborately adapted to $\mathrm{HAs}[42] . \mathrm{SPO}_{2}$ decreased with increasing altitude in the trekkers and Sherpas. However, $\mathrm{SPO}_{2}$ values were less decreased in the Sherpas than in the trekkers at each of the HAs. Similarly, a previous study observed that Tibetan mountaineers have a higher arterial $\mathrm{O}_{2}$ saturation than newcomers from a lower altitude who are acclimatized to living at HA (physiologically acclimatized subjects) at a simulated altitude of 5,000 $\mathrm{m}$ [43]. The physical and physiological characteristics of Sherpas, such as greater hypoxic and hypercapnic ventilatory responsiveness, larger lungs, and better lung function [44], may be associated with the attenuated decrease in $\mathrm{SPO}_{2}$ that was observed in this population as they trekked at HAs.

Despite the fact that there was no decrease in $\mathrm{SPO}_{2}$, an alteration in the CAR occurred at 1,100 $\mathrm{m}$ in the Sherpas. Because the morning at the $1,100 \mathrm{~m}$ lodge was the first workday morning for the Sherpas as guides, we hypothesized that the anticipatory stress prior to work [26] may have influenced HPA axis function in the Sherpas at 1,100 $\mathrm{m}$. No significant alterations in the CAR were found at HAs in the Sherpas during the trek on the Annapurna 
circuit. However, the available information on HPA axis function in Sherpas or other lineages that have adapted to HA living is limited. Previous studies have observed a blunted sympathoneural response to hypobaric hypoxemia in HA natives of Bolivia and the Andes $[45,46]$ and a blunt ACTH and cortisol response to exogenous CRH in HA natives of Andes [47]. Thus, the distinctive physical and physiological characteristics of HA natives are possible explanations for the observed differences in HPA axis and cardiovascular function between Sherpas and trekkers during the trek on the Annapurna circuit.

Taken together, we observed that the CAR changed at HAs, where a tachycardic response to HA was presented without apparent changes in the BP levels. The alterations of CAR, i.e. an elevated level of cortisol secretion at 3,540 and $3,800 \mathrm{~m}$ and a heightened pattern of cortisol secretion at $4,800 \mathrm{~m}$, occurred in the trekkers but not in the Sherpas. These changes in the levels and patterns of cortisol secretion after awakening resulted in an increase in the CARauc. It is likely that a massive surge-like release in cortisol after the awakening period has a role as a humoral signal that facilitates cardiovascular functions in nonacclimatized HA visitors through an increase in the gene expression of the $\mathrm{G}$ protein-linked receptors of potent vasoconstrictor hormones such as norepinephrine, angiotensin II, arginine vasopressin, and endothelin [48, 49]. We believe that the results of our study will be helpful in enhancing our understanding of the response of the HPA axis to hypobaric hypoxemia as well as our understanding of differences in the HPA axis and cardiovascular responses to hypobaric hypoxemia between visitors to and natives of HA regions.

\section{Acknowledgements}

This work was supported by the Korea Military Medical Research Project funded by the Ministry of National Defense of the Republic of Korea (2011-KMMRP-025). Our appreciation is expressed to Prof. Hyuk B. Kwon (Hormone Research Center of Chonnam National University) for help in the salivary cortisol RIA. Deep appreciation is also expressed to all participants of this study.

\section{Disclosure Statement}

The authors have no conflicts of interest to disclose.

\section{References}

1 Peacock AJ: ABC of oxygen: oxygen at high altitude. BMJ 1998;317:1063-1066.

- 2 Peers C, Wyatt CN, Evans AM: Mechanisms for acute oxygen sensing in the carotid body. Respir Physiol Neurobiol 2010;174:292-298.

3 Gonzalez C, Almaraz L, Obeso A, Rigual R: Oxygen and acid chemoreception in the carotid body chemoreceptors. Trends Neurosci 1992;15:146-153.

4 Sharp FR, Bernaudin M: HIF1 and oxygen sensing in the brain. Nat Rev Neurosci 2004; 5:437-448.

5 King TL, Heesch CM, Clark CG, Kline DD, Hasser EM: Hypoxia activates nucleus tractus solitarii neurons projecting to the paraventricular nucleus of the hypothalamus. Am J Physiol Regul Integr Comp Physiol 2012; 302:R1219-R1232.

-6 Herman JP, Cullinan WE, Ziegler DR, Tasker JG: Role of the paraventricular nucleus microenvironment in stress integration. Eur J Neurosci 2002;16:381-385.

7 Hainsworth R, Drinkhill MJ, Rivera-Chira M: The autonomic nervous system at high altitude. Clin Auton Res 2007;17:13-19.

8 Rostrup M: Catecholamines, hypoxia and high altitude. Acta Physiol Scand 1998;162: 389-399.

High Altitude-Induced Alterations in the CAR
9 Humpeler E, Skrabal F, Bartsch G: Influence of exposure to moderate altitude on the plasma concentration of cortisol, aldosterone, renin, testosterone, and gonadotropins. Eur J Appl Physiol Occup Physiol 1980;45:67-76.

10 Richalet JP, Rutgers V, Bouchet P, Rymer JC, Keromes A, Duval-Arnould G, Rathat C: Diurnal variations of acute mountain sickness, colour vision, and plasma cortisol and ACTH at high altitude. Aviat Space Environ Med 1989;60:105-111.

11 Sawhney RC, Malhotra AS, Singh T: Glucoregulatory hormones in man at high altitude. Eur J Appl Physiol Occup Physiol 1991;62: 286-291.

12 Benso A, Broglio F, Aimaretti G, Lucatello B, Lanfranco F, Ghigo E, Grottoli S: Endocrine and metabolic responses to extreme altitude and physical exercise in climbers. Eur J Endocrinol 2007; 157:733-740.

13 McLean CJ, Booth CW, Tattersall T, Few JD: The effect of high altitude on saliva aldosterone and glucocorticoid concentrations. Eur J Appl Physiol Occup Physiol 1989;58:341-347.

$\checkmark 14$ Pruessner JC, Wolf OT, Hellhammer DH, Buske-Kirschbaum A, von Auer K, Jobst S, Kaspers F, Kirschbaum C: Free cortisol levels after awakening: a reliable biological marker for the assessment of adrenocortical activity. Life Sci 1997;61:2539-2549.
15 Clow A, Hucklebridge F, Thorn L: The cortisol awakening response in context. Int Rev Neurobiol 2010;93:153-175.

16 Buijs RM, van Eden CG, Goncharuk VD, Kalsbeek A: The biological clock tunes the organs of the body: timing by hormones and the autonomic nervous system. J Endocrinol 2003;177:17-26.

17 Fries E, Dettenborn L, Kirschbaum C: The cortisol awakening response: facts and future directions. Int J Psychophysiol 2009;72:6773.

18 Mazzeo RS, Child A, Butterfield GE, Mawson JT, Zamudio S, Moore LG: Catecholamine response during 12 days of high-altitude exposure (4,300 m) in women. J Appl Physiol 1998; 84:1151-1157.

19 Di Luigi L, Baldari C, Sgro P, Emerenziani GP, Gallotta MC, Bianchini S, Romanelli F, Pigozzi F, Lenzi A, Guidetti L: The type 5 phosphodiesterase inhibitor tadalafil influences salivary cortisol, testosterone, and dehydroepiandrosterone sulphate responses to maximal exercise in healthy men. J Clin Endocrinol Metab 2008;93:3510-3514.

20 Ahn RS, Choi JH, Choi BC, Kim JH, Lee SH, Sung SS: Cortisol, $17 \beta$-estradiol, and progesterone secretion within the first hour after awakening in women with regular menstrual cycles. J Endocrinol 2011;211:285-295. 
-21 Pruessner JC, Kirschbaum C, Meinlschmid G, Hellhammer DH: Two formulas for computation of the area under the curve represent measures of total hormone concentration versus time-dependent change. Psychoneuroendocrinology 2003;28:916-931.

-22 Wust S, Wolf J, Hellhammer DH, Federenko I, Schommer N, Kirschbaum C: The cortisol awakening response - normal values and confounds. Noise Health 2000;2:79-88.

23 Kunz-Ebrecht, SR, Kirschbaum C, Marmot $\mathrm{M}$, Steptoe A: Differences in cortisol awakening response on work days and weekends in women and men from the Whitehall II cohort. Psychoneuroendocrinology 2004;29: 516-528.

-24 Okun ML, Krafty RT, Buysse DJ, Monk TH, Reynolds CF 3rd, Begley A, Hall M: What constitutes too long of a delay? Determining the cortisol awakening response using selfreport and PSG-assessed wake time. Psychoneuroendocrinology 2010;35:460-468.

-25 Adam EK, Hawkley LC, Kudielka BM, Cacioppo JT: Day-to-day dynamics of experience - cortisol associations in a populationbased sample of older adults. Proc Natl Acad Sci USA 2006;103:17058-1706.

-26 Schlotz W, Hellhammer J, Schulz P, Stone AA: Perceived work overload and chronic worrying predict weekend-weekday differences in the cortisol awakening response. Psychosom Med 2004;66:207-214.

-27 Ehrhart-Bornstein M, Hinson JP, Bornstein SR, Scherbaum WA, Vinson GP: Intra-adrenal interactions in the regulation of adrenocortical steroidogenesis. Endocr Rev 1998;19: 101-143.

28 Giussani DA, McGarrigle HH, Moore PJ, Bennet L, Spencer JA, Hanson MA: Carotid sinus nerve section and the increase in plasma cortisol during acute hypoxia in fetal sheep. J Physiol 1994;477:75-80.

29 McDonald TJ, Nathanielsz PW: The involvement of innervation in the regulation of fetal adrenal steroidogenesis. Horm Metab Res 1998;30:297-302.
30 Mazzeo RS, Bender PR, Brooks GA, Butterfield GE, Groves BM, Sutton JR, Wolfel EE, Reeves JT: Arterial catecholamine responses during exercise with acute and chronic highaltitude exposure. Am J Physiol 1991; 261:E419-E424.

31 Mazzeo RS, Wolfel EE, Butterfield GE, Reeves JT: Sympathetic response during 21 days at high altitude $(4,300 \mathrm{~m})$ as determined by urinary and arterial catecholamines. Metabolism 1994;43:1226-1232.

32 Surks MI, Beckwitt HJ, Chidsey CA: Changes in plasma thyroxine concentration and metabolism, catecholamine excretion and basal oxygen consumption in man during acute exposure to high altitude. J Clin Endocrinol Metab 1967;27:789-799.

33 Lehoux JG, Fleury A, Ducharme L: The acute and chronic effects of adrenocorticotropin on the levels of messenger ribonucleic acid and protein of steroidogenic enzymes in rat adrenal in vivo. Endocrinology 1998;139:39133922.

34 Ehrhart-Bornstein M, Bornstein SR, Gonzalez-Hernández J, Holst JJ, Waterman MR, Scherbaum WA: Sympathoadrenal regulation of adrenocortical steroidogenesis. Endocr Res 1995;21:13-24.

35 Nishijima MK, Breslow MJ, Raff H, Traystman RJ: Regional adrenal blood flow during hypoxia in anesthetized, ventilated dogs. Am J Physiol 1989;256:H94-H100.

-36 Ligier B, Breslow MJ, Clarkson K, Raff H, Traystman RJ: Adrenal blood flow and secretory effects of adrenergic receptor stimulation. Am J Physiol 1994;266:H220-H227.

- 37 Breslow MJ, Ball TD, Miller CF, Raff H, Traystman RJ: Adrenal blood flow and secretory relationships during hypoxia in anesthetized dogs. Am J Physiol 1989;257:H1458H1465.

38 Bloom SR, Edwards AV, Hardy RN: Adrenal and pancreatic endocrine responses to hypoxia and hypercapnia in the calf. J Physiol 1977; 269:131-154.
39 Koller EA, Drechsel S, Hess T, Macherel P, Boutellier U: Effects of atropine and propranolol on the respiratory, circulatory, and ECG responses to high altitude in man. Eur J Appl Physiol Occup Physiol 1988;57:163-172.

40 Bernardi L, Passino C, Spadacini G, Calciati A, Robergs R, Greene R, Martignoni E, Anand I, Appenzeller O: Cardiovascular autonomic modulation and activity of carotid baroreceptors at altitude. Clin Sci (Lond) 1998;95:565573.

41 Stalder T, Evans P, Hucklebridge F, Clow A: Associations between the cortisol awakening response and heart rate variability. Psychoneuroendocrinology 2011;36:454-462.

42 Moore LG, Niermeyer S, Zamudio S: Human adaptation to high altitude: regional and lifecycle perspectives. Am J Phys Anthropol 1998;41(suppl 27): 25-64.

43 Pływaczewski R, Wu TY, Wang XQ, Cheng HW, Sliwinski PS, Zielinski J: Sleep structure and periodic breathing in Tibetans and Han at simulated altitude of 5,000 m. Respir Physiol Neurobiol 2003;136:187-197.

$44 \mathrm{Wu}$ T, Kayser B: High altitude adaptation in Tibetans. High Alt Med Biol 2006;7:193-208.

-45 Antezana AM, Richalet JP, Noriega I, Galarza $\mathrm{M}$, Antezana G: Hormonal changes in normal and polycythemic high-altitude natives. J Appl Physiol 1995;79:795-800.

46 Favier R, Desplanches D, Hoppeler H, Caceres E, Grunenfelder A, Koubi H, Leuenberger M, Sempore B, Tuscher L, Spielvogel H: Hormonal and metabolic adjustments during exercise in hypoxia or normoxia in highland natives. J Appl Physiol 1996;80:632-637.

47 Ramirez G, Herrera R, Pineda D, Bittle PA, Rabb HA, Bercu BB: The effects of high altitude on hypothalamic-pituitary secretory dynamics in men. Clin Endocrinol (Oxf) 1995; 43:11-18

48 Morris AJ, Malbon CC: Physiological regulation of $\mathrm{G}$ protein-linked signaling. Physiol Rev 1999;79:1373-1430.

49 Ullian ME: The role of corticosteroids in the regulation of vascular tone. Cardiovasc Res 1999;41:55-64. 